\title{
Anti-inflammatory potential of peat moss extracts in lipopolysaccharide-stimulated RAW 264.7 macrophages
}

\author{
WOO-SUK CHOI $^{1 *}$, JIN-WOO JEONG ${ }^{2,3 *}$, SUNG OK KIM ${ }^{4}$, GI-YOUNG KIM ${ }^{5}$, BYUNG-WOO KIM ${ }^{3,6}$, \\ CHEOL MIN KIM ${ }^{7}$, YONG-BAE SEO ${ }^{1}$, WOE-YEON KIM ${ }^{8}$, SANG-YEOL LEE $^{8}$, KWON-HO JO $^{9}$, \\ YOUNG JU CHOI ${ }^{10}$, YUNG HYUN CHOI ${ }^{2,3}$ and GUN-DO KIM ${ }^{1}$ \\ ${ }^{1}$ Department of Microbiology, College of Natural Sciences, Pukyong National University, Busan 608-737; \\ ${ }^{2}$ Department of Biochemistry, Dongeui University College of Oriental Medicine, Busan 614-052; \\ ${ }^{3}$ Anti-Aging Research Center and Blue-Bio Industry RIC, Dongeui University, Busan 614-714; \\ ${ }^{4}$ Department of Herbal Pharmacology, Daegu Haany University College of Oriental Medicine, Daegu 706-828; \\ ${ }^{5}$ Laboratory of Immunobiology, Department of Marine Life Sciences, Jeju National University, Jeju 690-756; \\ ${ }^{6}$ Department of Life Science and Biotechnology, Dongeui University, Busan 614-714; ${ }^{7}$ Department of Biochemistry, \\ Busan National University College of Medicine, Yangsan 626-870; ${ }^{8}$ Division of Applied Life Science, \\ Plant Molecular Biology and Biotechnology Research Center, Gyeongsang National University, Jinju 660-701; \\ ${ }^{9}$ Green Vortex Co., Ltd., Busanjin-gu, Busan 614-714; ${ }^{10}$ Department of Food and Nutrition, \\ College of Medical Life Sciences, Silla University, Busan 617-736, Republic of Korea
}

Received March 7, 2014; Accepted July 17, 2014

DOI: $10.3892 / \mathrm{ijmm} .2014 .1881$

\begin{abstract}
The aim of the present study was to identify the anti-inflammatory and anti-oxidative effects of peat moss aqueous extract (PME) on lipopolysaccharide (LPS)stimulated RAW 264.7 macrophages. To demonstrate the anti-inflammatory and antioxidant effects of PME, the levels of nitric oxide (NO) and cytokines were measured using Griess reagent and cytokine ELISA kits, respectively. Reverse transcriptase-polymerase chain reaction (RT-PCR) and western blot analysis were conducted to evaluate the expression of genes and proteins. Immunofluorescence was used to measure the expression and translocation of transcription factors. Pre-treatment with PME inhibited the production of prostaglandin $\mathrm{E}_{2}$ and $\mathrm{NO}$ by suppressing the gene expression of cyclooxygenase- 2 and inducible NO synthase, respectively.
\end{abstract}

Correspondence to: Professor Gun-Do Kim, Department of Microbiology, College of Natural Sciences, Pukyong National University, 45 Yongso-ro, Nam-gu, Busan 608-737, Republic of Korea

E-mail: gundokim@pknu.ac.kr

Professor Yung Hyun Choi, Department of Biochemistry, Dongeui University College of Oriental Medicine 52-57, Yangjeong-ro, Busanjin-gu, Busan 614-052, Republic of Korea

E-mail: choiyh@deu.ac.kr

*Contributed equally

Key words: peat moss, anti-inflammation, nuclear factor- $\mathrm{kB}$, mitogenactivated protein kinase, nuclear factor-like 2/heme oxygenase-1
The LPS-stimulated gene expression and the production of tumor necrosis factor- $\alpha$ and interleukin-1 $\beta$ were significantly reduced by PME. In the LPS-stimulated RAW 264.7 cells, nuclear factor- $\kappa \mathrm{B}(\mathrm{NF}-\kappa \mathrm{B})$ translocated from the cytosol to the nucleus, while pre-treatment with PME induced the sequestration of NF- $\kappa \mathrm{B}$ in the cytosol through the inhibition of $\mathrm{I} \kappa \mathrm{B} \alpha$ degradation. In the same manner, PME contributed to the inhibition of the activation of mitogen-activated protein kinases. In addition, the PME-treated RAW 264.7 cells facilitated the activation of nuclear factor-like 2 (Nrf2), and in turn, enhanced heme oxygenase-1 (HO-1) expression. These results indicate that PME exerts anti-inflammatory and antioxidant effects, and suggest that PME may neutralize inflammation and prevent cellular damage by oxidative stress.

\section{Introduction}

Inflammation is an immune response to recover injured or infected tissue. Under injury and infection, various factors, such as cytokines and chemokines, are secreted by immune cells and the cells are transferred to the area to resolve the abnormal condition. The characteristics of inflammatory response have been observed from the ancient era, and are still being extensively studied in order to determine the correlation between various diseases and inflammation (1). During inflammation, inducible nitric oxide (NO) synthase (iNOS) and cyclooxygenase-2 (COX-2) play important roles in amplifying the inflammatory response. The enzymatic activity of iNOS converts larginine to NO (2). iNOS is expressed in response to interleukin-1 $\beta$ (IL-1 $\beta$ ), tumor necrosis factor- $\alpha$ (TNF- $\alpha$ ), interferon $-\gamma$ and lipopolysaccharide (LPS). NO is beneficial in eliminating microorganisms and improving the blood supply 
to injured tissue; however, it can cause tissue damage when it forms the highly reactive peroxynitrite by reacting with reactive oxygen species (ROS) (3). COX-2, an inducible form of COXs, is overexpressed in LPS-stimulated macrophages. It carries out an enzymatic role, transforming arachidonic acid to prostaglandin $\mathrm{E}_{2}\left(\mathrm{PGE}_{2}\right)$ (4). During the inflammatory response, $\mathrm{NO}$ increases $\mathrm{COX}$ activity, resulting in an increase in the production of pro-inflammatory prostagalandins (PGs) including $\mathrm{PGE}_{2}$. Consequently, the inflammatory response is exacerbated (5).

Although inflammation is a solution to normalize troubled tissue, immune dysfunction can convert inflammation into a weapon which causes chronic inflammatory diseases. Rheumatoid arthritis (RA) is a representative chronic inflammatory disease characterized by synovial inflammation, the hyperplasia of synovial tissues and the destruction of bone and cartilage, contributing to joint disability. For patients with RA, TNF- $\alpha$ inhibitors are mainly used to inhibit inflammatory responses, resulting in the reduction of symptom aggravation $(6,7)$. In the 19 th century, the mud bath, a folk remedy, was used to ameliorate the symptoms of RA. A mud bath involves plant-derived sediments, termed humic substances. The sediments are produced through a humification process in the environment. The process synthesizes and decomposes humic substances. As a result, stable compounds remain in the sediments. Examples of plant-derived sediments include peat, sapropel and mumie. Among the plant-derived sediments, peat is a light brown to black organic material produced under marshy conditions from decomposed waterlogged vegetation, including mosses (8-10). Based on the traditional remedy, the pharmacological effects of sediments have been demonstrated in vivo and in vitro. In previous studies, humate, a derivative from bituminous or brown coal, has been shown to exert anti-inflammatory effects, including the inhibition of hypersensitivity in rats (11), of the granulation and adhesion of neutrophils (12), and of cytokine expression and complement production of mononuclear lymphocytes (13).

There are several studies available demonstrating the pharmacological effects of coal-derived sediments (11-13); however, to the best of our knowledge, the anti-inflammatory properties of peat moss extracts have not been investigated to date. In the present study, we aimed to investigate the antiinflammatory effects of peat moss aqueous extracts (PME) on inflamed RAW 264.7 macrophages at the molecular level, as well as to identify the signal transduction pathways involved.

\section{Materials and methods}

Preparation of PME. Peat moss extracts were a kind gift from Green Voltex Co. (Busan, Korea). Briefly, the peat moss was powdered, and then filtered using 6-mesh screen. Ground peat moss $(100 \mathrm{~g})$ and sodium bicarbonate $(5 \mathrm{~g})$ were mixed and fermented at $30^{\circ} \mathrm{C}$ for 5 to 7 days until reaching $\mathrm{pH}$ 7.0. The PME from the fermented peat moss was prepared with hot distilled water $\left(60^{\circ} \mathrm{C}\right)$ for $24 \mathrm{~h}$, stirring 4-5 times during this period. The infusates were filtered through Whatman No 4 paper and then centrifuged at 13,200 rpm. The total volume was measured and the extraction yield (11.1 g) determined with the dry weight of $1 \mathrm{ml}$ duplicate samples. The extracts were dried at $30^{\circ} \mathrm{C}$ before being used in the experiments.
Cell culture. The RAW 264.7 cells, murine macrophage-like cells, were purchased from the American Tissue Culture Collection (ATCC, Manassas, VA, USA). The cells were grown in Dulbecco's modified Eagle's medium (DMEM) supplemented with $10 \%$ fetal bovine serum (FBS) and $1 \%(\mathrm{v} / \mathrm{v})$ penicillin $(100 \mathrm{U} / \mathrm{ml}) /$ streptomycin $(100 \mu \mathrm{g} / \mathrm{ml})$ under humidified conditions of $5 \% \mathrm{CO}_{2}$ at $37^{\circ} \mathrm{C}$. The RAW 264.7 cells were stimulated to induce an inflammatory response using LPS which as purchased from Sigma-Aldrich Chemical Co. (St. Louis, MO, USA). DMEM, FBS and penicillin/streptomycin were purchased from Cellgro Mediatech (Manassas, VA, USA).

Cell viability assay. Cell viability was measured by 3-(4,5dimethylthiazol-2-yl)-2,5-diphenyltetrazolium bromide (MTT) assay. Briefly, the RAW 264.7 cells $\left(5 \times 10^{5}\right.$ cells $\left./ \mathrm{ml}\right)$ were seeded in a 96-well plate. The cells were incubated with 10, 25 and $50 \mu \mathrm{g} / \mathrm{ml}$ PME for $24 \mathrm{~h}$ or were pre-treated with $50 \mu \mathrm{g} / \mathrm{ml} \mathrm{PME}$ for $1 \mathrm{~h}$ and then stimulated with $500 \mathrm{ng} / \mathrm{ml} \mathrm{LPS} \mathrm{or} 1 \mathrm{mM} \mathrm{H}_{2} \mathrm{O}_{2}$ for $24 \mathrm{~h}$. Following incubation with PME, LPS and $\mathrm{H}_{2} \mathrm{O}_{2}$, the cultured medium was changed to fresh medium and the cells were incubated with $0.5 \mathrm{mg} / \mathrm{ml} \mathrm{MTT}$ solution (Sigma-Aldrich Chemical Co. ) for $2 \mathrm{~h}$. Subsequently, the supernatant was discarded and formazan blue, which was formed in the cells, was dissolved with DMSO. The optical density was measured at $540 \mathrm{~nm}$ using a microplate reader (Dynatech Laboratories, Chantilly, VA, USA). The assay was performed in triplicate.

Nitrite measurement. The RAW 264.7 cells were seeded in each well of a 96-well plate. The cells were treated solely with PME $(10,25$ and $50 \mu \mathrm{g} / \mathrm{ml})$ for $24 \mathrm{~h}$ or were pre-treated with $50 \mu \mathrm{g} / \mathrm{ml}$ PME for $1 \mathrm{~h}$ and stimulated with $500 \mathrm{ng} / \mathrm{ml}$ LPS. Following incubation for $24 \mathrm{~h}$, the supernatant of each well was mixed with the same volume of Griess reagent (Sigma-Aldrich Chemical Co.) for $10 \mathrm{~min}$ at room temperature in the dark. The absorbance of the reacted supernatant was measured at $540 \mathrm{~nm}$ using a microplate reader. All samples were conducted in triplicate.

$P G E_{2}, T N F-\alpha$ and $I L-1 \beta$ measurement. To measure the inhibitory effects of PME on the production of $\mathrm{PGE}_{2}, \mathrm{TNF}-\alpha$ and IL-1 $\beta$, enzyme-linked immunosorbent assay (ELISA) kits were purchased from Cayman Chemical Co. (Ann Arbor, MI, USA) for $\mathrm{PGE}_{2}$, and from R\&D Systems Inc. (Minneapolis, MN, USA) for TNF- $\alpha$ and IL-1 $\beta$. The cell culture conditions were same as those for the nitrite measurement assay. Following incubation with PME and LPS for $24 \mathrm{~h}$, the concentration of $\mathrm{PGE}_{2}$, TNF- $\alpha$ and IL- $1 \beta$ in the culture medium was determined by selective ELISA kits.

Reverse transcription-polymerase chain reaction ( $R T-P C R)$. The cells were incubated with PME $(10,25$ and $50 \mu \mathrm{g} / \mathrm{ml})$ alone for $24 \mathrm{~h}$ or pre-treated with $50 \mu \mathrm{g} / \mathrm{ml}$ PME for $1 \mathrm{~h}$ prior to LPS stimulation for $24 \mathrm{~h}$. Total RNA was isolated from the cultured cells using TRIzol reagent (Invitrogen, Carlsbad, CA, USA). One microgram of total RNA was used for cDNA synthesis using AccuPower ${ }^{\circledR}$ RT premix (Bioneer, Daejeon, Korea) containing M-MLV reverse transcriptase. The iNOS, COX-2 and glyceraldehyde-3-phosphate dehydrogenase (GAPDH; used as an internal control) genes, were amplified from the cDNA by PCR. The PCR primers were as follows: iNOS 
(5'-ATG TCC GAA GCA AAC ATC AC-3' and 5'-TAA TGT CCA GGA AGT AGG TG-3'), COX-2 (5'-ATG GTC AGT AGA CTT TTA CGA CTA-3' and 5'-GGA GAG ACT ATC AAG ATA GTG ATC-3'), IL-1ß (5'-GGG CTG CTT CCA AAC CTT TG-3' and 5'-GCT TGG GAT CCA CAC TCT CC-3'), TNF- $\alpha$ (5'-TCT CAT CAG TTC TAT GGC CC-3' and 5'-GGG AGT AGA CAA GGT ACA AC-3'), and GAPDH (5'-AGG CCG GTG CTG AGT ATG TC-3' and 5'-TGC CTG CTT CAC CAC CTT CT-3'). The amplified DNA was visualized on an agarose gel containing ethidium bromide $(\mathrm{EtBr}$; Sigma-Aldrich Chemical Co.).

Western blot analysis. The cells were cultured with or without PME for $1 \mathrm{~h}$ prior to stimulation with $500 \mathrm{ng} / \mathrm{ml}$ LPS for $24 \mathrm{~h}$. The control group was cultured in medium without PME and were not treated with LPS. For total protein extraction, the cells were lysed with lysis buffer $[25 \mathrm{mM}$ Tris-Cl (pH 7.5), $250 \mathrm{mM} \mathrm{NaCl}, 5 \mathrm{mM}$ ethylenediaminetetraacetic acid (EDTA), $1 \%$ NP-40, $1 \mathrm{mM}$ pheny-methylsulfonyl fluoride (PMSF) and $5 \mathrm{mM}$ dithiothreitol (DTT)] for $1 \mathrm{~h}$. Insoluble materials were discarded by centrifugation at $14,00 \mathrm{rpm}$ for $20 \mathrm{~min}$ at $4^{\circ} \mathrm{C}$. In a parallel experiment, nuclear and cytosloic proteins were prepared using nuclear extraction reagents (Pierce, Rockford, IL, USA) according to the manufacturer's instructions. The protein concentration in the cell lysate was determined using detergent-compatible protein assay from Bio-Rad Laboratories (Hercules, CA, USA). Equal amounts of protein were separated on sodium dodecyl sulfate (SDS)-polyacrylamide gels. The separated protein was transferred to nitrocellulose membranes (Schleicher \& Schuell, Keene, NH, USA) and subsequently blocked with Tris-buffered saline (10 mM Tris-Cl, $\mathrm{pH}$ 7.4) containing $0.5 \%$ Tween-20 and 5\% non-fat dry milk for $1 \mathrm{~h}$ at room temperature. The protein was probed with primary antibodies overnight at $4{ }^{\circ} \mathrm{C}$. After probing with the primary antibodies, the membranes were incubated with horseradish peroxidase-conjugated anti-rabbit $\operatorname{IgG}$ as the secondary antibody, purchased from Amersham Corp. (Arlington Heights, IL, USA). Using the enhanced chemiluminescence (ECL) detection system (Amersham Corp.), immunoreactive bands were detected and exposed to X-ray film. All primary antibodies, including antibodies to iNOS, COX-2, nuclear factor (NF)- $\mathrm{KB}$, I $\mathrm{B} \alpha, \mathrm{p} 38$, extracellular signal-regulated kinase (ERK), c-Jun NH2-terminal kinase (JNK), Akt and heme oxygenase-1 (HO-1) were purchased from Cell Singnaling Technology (Beverly, MA, USA) apart from nuclear factor erythroid 2-related factor 2 (Nrf2) which was from Abcam (Cambridge, UK).

Immunofluorescence staining. The RAW 264.7 cells were seeded on coverslip bottom dishes for $24 \mathrm{~h}$. The cells pre-treated with $50 \mu \mathrm{g} / \mathrm{ml}$ PME for 30 min prior to LPS stimulation for $30 \mathrm{~min}$. Following incubation with PME and LPS, 4',6-diamidino-2-phenylindole (DAPI; Roche Diagnostics Corp., Indianapolis, IN, USA) staining was conducted for $15 \mathrm{~min}$, and 4\% paraformaldehyde (Junsei Chemical Co., Ltd., Tokyo, Japan) was used for fixing the DAPIstained cells. The fixed cells were blocked with 5\% mouse and rabit serum (Santa Cruz Biotechnology Inc., Santa Cruz, CA, USA), and then antibodies for p65 or Nrf2 (1 $\mu \mathrm{g} / \mathrm{well})$ and $0.3 \%$ Triton X-100 were applied for $1 \mathrm{~h}$. The cells were incubated with Alexa Fluor 488-tagged anti-rabbit IgG (Cell Signaling

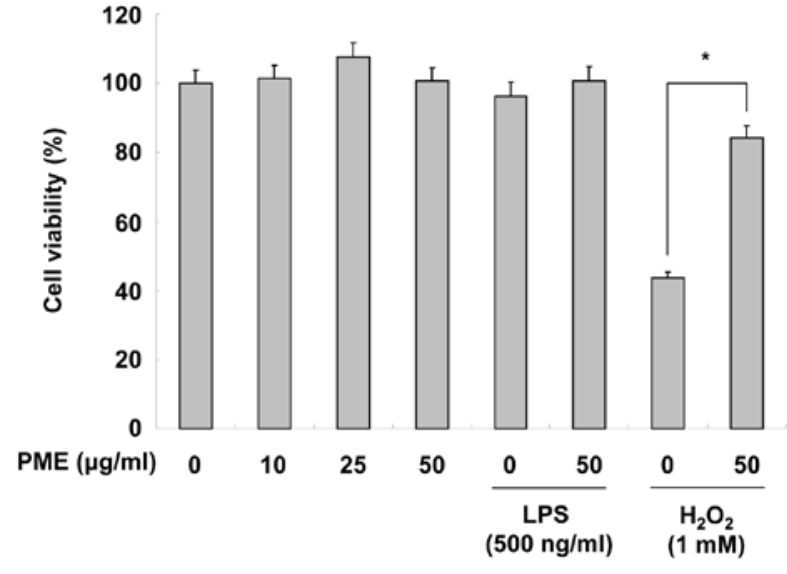

Figure 1. Effects of peat moss aqueous extract (PME) on the viability of RAW 264.7 cells. Cell viability was measured by MTT assay, and was not significantly impaired by treatment with PME $(10,25$ and $50 \mu \mathrm{g} / \mathrm{ml})$ and lipopolysaccharide (LPS) $(500 \mathrm{ng} / \mathrm{ml})$ alone. Cell viability was reduced by $1 \mathrm{mM}$ $\mathrm{H}_{2} \mathrm{O}_{2}$, whereas pre-treatment with PME suppressed $\mathrm{H}_{2} \mathrm{O}_{2}$-induced cell death. Values are the means \pm SD. ${ }^{*} \mathrm{P}<0.05$ compared with the $\mathrm{H}_{2} \mathrm{O}_{2}$-treated group.

Technology, Berverly, MA, USA) for $1 \mathrm{~h}$, and were embedded with ProLong Antifade Reagent (Invitrogen, Eugene, OR, USA). The cells were observed using a Nikon Eclipse 50i microscope equipped with a charged-coupled device camera (Nikon, Tokyo, Japan). To determine the subcellular regions of protein co-localization, individual red-, blue- and greenstained images derived from the same field were merged using with High-Content Analysis software (Cambridge Healthtech Institute, Needham, MA, USA). Densitometric analysis of the stained cells was evaluated using ImageJ software.

Data analysis. Results are expressed as the means \pm standard deviation (SD). Differences in mean values between groups were analyzed by a one-way analysis of variance followed by Dunnett's test. Differences were considered statistically significant with P-values $<0.05$.

\section{Results}

Cytotoxicity of peat moss extracts. Before analyzing the antiinflammatory effects of PME, we examined the cytotoxic effects of PME on RAW 264.7 cells by MTT assay. Teatment with PME $(10,25$ and $50 \mu \mathrm{g} / \mathrm{ml})$ did not appear cytotoxic to the RAW 264.7 cells. Stimulation with LPS $(500 \mathrm{ng} / \mathrm{ml})$ also did not have any particular cytotoxic effect on the cells. When the cells were treated with $\mathrm{H}_{2} \mathrm{O}_{2}$, cell viability markedly decreased; however, pre-treatment with PME inhibited the cytotoxic effects of $\mathrm{H}_{2} \mathrm{O}_{2}$ on the RAW 264.7 cells (Fig. 1). Hence, these results indicate that PME does not have any cytotoxic effects and prevents oxidative stress.

Regulatory effects of PME on the production of $N O$ and $P G E_{2}$. To investigate the regulatory effects of PME on the production of $\mathrm{NO}$ and $\mathrm{PGE}_{2}$, the RAW 264.7 cells were treated with the indicated concentrations of PME. As shown in Fig. 2A, the RAW 264.7 cells did not produce NO following treatment with PME alone. LPS stimulation increased NO production as compared to the basal levels without LPS. Pre-treatment 

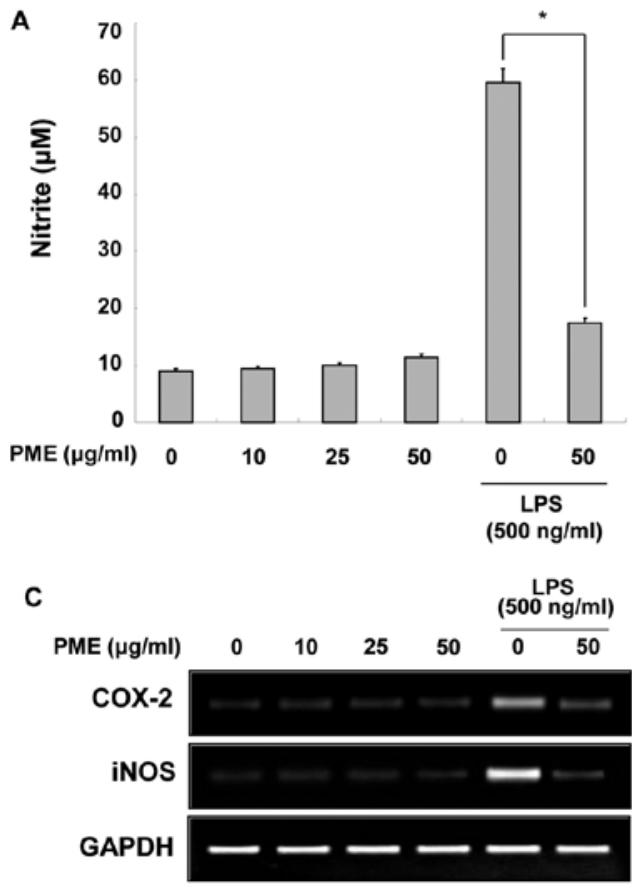

B

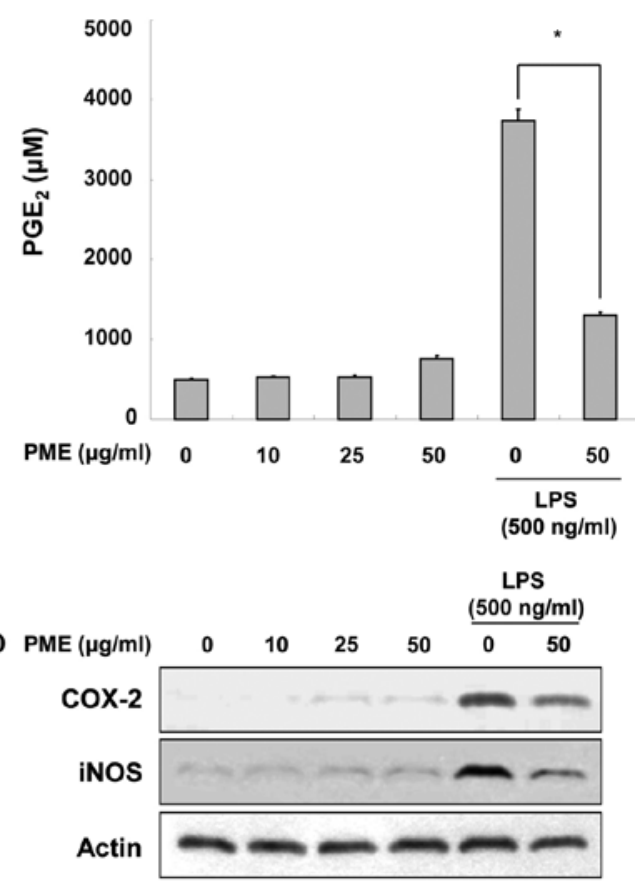

Figure 2. Effects of peat moss aqueous extract (PME) on lipopolysaccharide (LPS)-induced nitric oxide (NO) and prostaglandin $\mathrm{E}_{2}\left(\mathrm{PGE}_{2}\right)$ production, and LPS-induced inducible NO synthase (iNOS) and cyclooxygenase-2 (COX-2) expression. RAW 264.7 cells were pre-treated with PME at 10, 25 and $50 \mu \mathrm{g} / \mathrm{ml}$ for $1 \mathrm{~h}$ and then stimulated with LPS $(500 \mathrm{ng} / \mathrm{ml})$ for $24 \mathrm{~h}$. (A) NO levels were measured using Griess reagent. (B) PGE $\mathrm{P}_{2}$ production was measured by ELISA. Values are the means $\pm \mathrm{SD}$. ${ }^{*} \mathrm{P}<0.05$ compared with the LPS-treated group. (C and D) The mRNA and protein levels of iNOS and COX-2 were determined by RT-PCR and western blot analysis, respectively. GAPDH and actin were used as internal controls for RT-PCR and western blot analysis, respectively.

with $50 \mu \mathrm{g} / \mathrm{ml}$ PME inhibited the production of $\mathrm{NO}$ in the LPS-stimulated RAW 264.7 cells. Similar to NO production, treatment with PME did not induce a particular increase in $\mathrm{PGE}_{2}$ levels in the intact RAW 264.7 cells (Fig. 2B). LPS stimulation increased $\mathrm{PGE}_{2}$ production; however, treatment with PME prior to LPS stimulation suppressed PGE $_{2}$ amplification. Since the production of $\mathrm{NO}$ and $\mathrm{PGE}_{2}$ was inhibited by $\mathrm{PME}$, we examined whether PME alters the expression of iNOS and COX-2 at the mRNA and protein levels. In the RAW 264.7 cells not stimulated with LPS, PME did not induce iNOS and COX-2 expression at the mRNA and protein levels. The stimulation of RAW 264.7 cells with LPS enhanced iNOS and COX-2 expression; however, the pre-treatment with PME inhibited iNOS and COX-2 expression (Fig. 2C). These results indicate that $\mathrm{PME}$ decreases $\mathrm{NO}$ and $\mathrm{PGE}_{2}$ production in LPS-stimulated RAW 264.7 cells by inhibiting iNOS and COX-2 expression, respectively. Additionally, PME regulates the expression of iNOS and COX-2 at the transcriptional level.

Regulatory effects of PME on the production of pro-inflammatory cytokines. To identify the anti-inflammatory properties of PME, we quantified the production of IL- $1 \beta$ and TNF- $\alpha$ in the cultured medium. When the RAW 264.7 cells were treated solely with PME, there were not particularly changes in cytokine production. The production of IL-1 $\beta$ and TNF- $\alpha$ was increased by LPS stimulation; however, pre-treatment with PME decreased cytokine production in the LPS-stimulated RAW 264.7 cells (Fig. 3A and B). As cytokine secretion was reduced by PME treatment, we evaluated whether PME negatively regulates the mRNA synthesis of cytokines in the cells. As shown by RT-PCR, the mRNA expression of the cytokines was downregulated following pre-treatment with PME (Fig. 3C). Based on these results, we identified that PME negatively regulates the production of pro-inflammatory cytokines, including IL-1 $\beta$ and TNF- $\alpha$, at the transcriptional level.

Regulatory effects of PME on $N F-\kappa B$ activation. As shown by our results, the expression of iNOS, COX-2 and pro-inflammatory cytokines, including TNF- $\alpha$ and IL- $1 \beta$, was regulated at the transcriptional level through PME treatment. Based on these results, we evaluated the expression of nuclear p65, a subunit of NF- $\kappa \mathrm{B}$ and cytosolic $\mathrm{I} \kappa \mathrm{B} \alpha$ by western blot analysis and immunofluorescence. Before evaluating the inhibitory effects of PME on p65 translocation, we investigated whether treatment with PME alone induces the activation of p65. As shown in Fig. 4A, nuclear p65 expression was not specifically amplified by PME. Stimulation with LPS gradually increased nuclear p65 expression in a time-dependent manner. However, pre-treatment with PME reduced the expression of nuclear p65, which had returned to basal levels at 30 min of treatment with PME. In the same manner, LPS stimulation decreased $\mathrm{I} \kappa \mathrm{B} \alpha$ expression in the cytosol in a time-dependent manner; however, pre-treatment with PME somewhat amplified cytosolic $\mathrm{I} \kappa \mathrm{B} \alpha$ expression at $30 \mathrm{~min}$. In order to confirm $\mathrm{NF}-\kappa \mathrm{B}$ inactivation by PME, we visualized the location of $\mathrm{NF}-\kappa \mathrm{B}$ in the cells by immunofluorescence staining. In the control group (medium only) and PME-treated group, NF- $\kappa \mathrm{B}$ was located in the cytosol. LPS stimulation facilitated the translocation of $\mathrm{NF}-\kappa \mathrm{B}$ into the nucleus. In the group pre-treated with PME and then with LPS, NF- $\kappa \mathrm{B}$ was arrested in cytosolic area (Fig. 4B). Densitometric analysis of the nuclear area showed that nuclear p65 density was amplified 10 -fold by LPS stimula- 

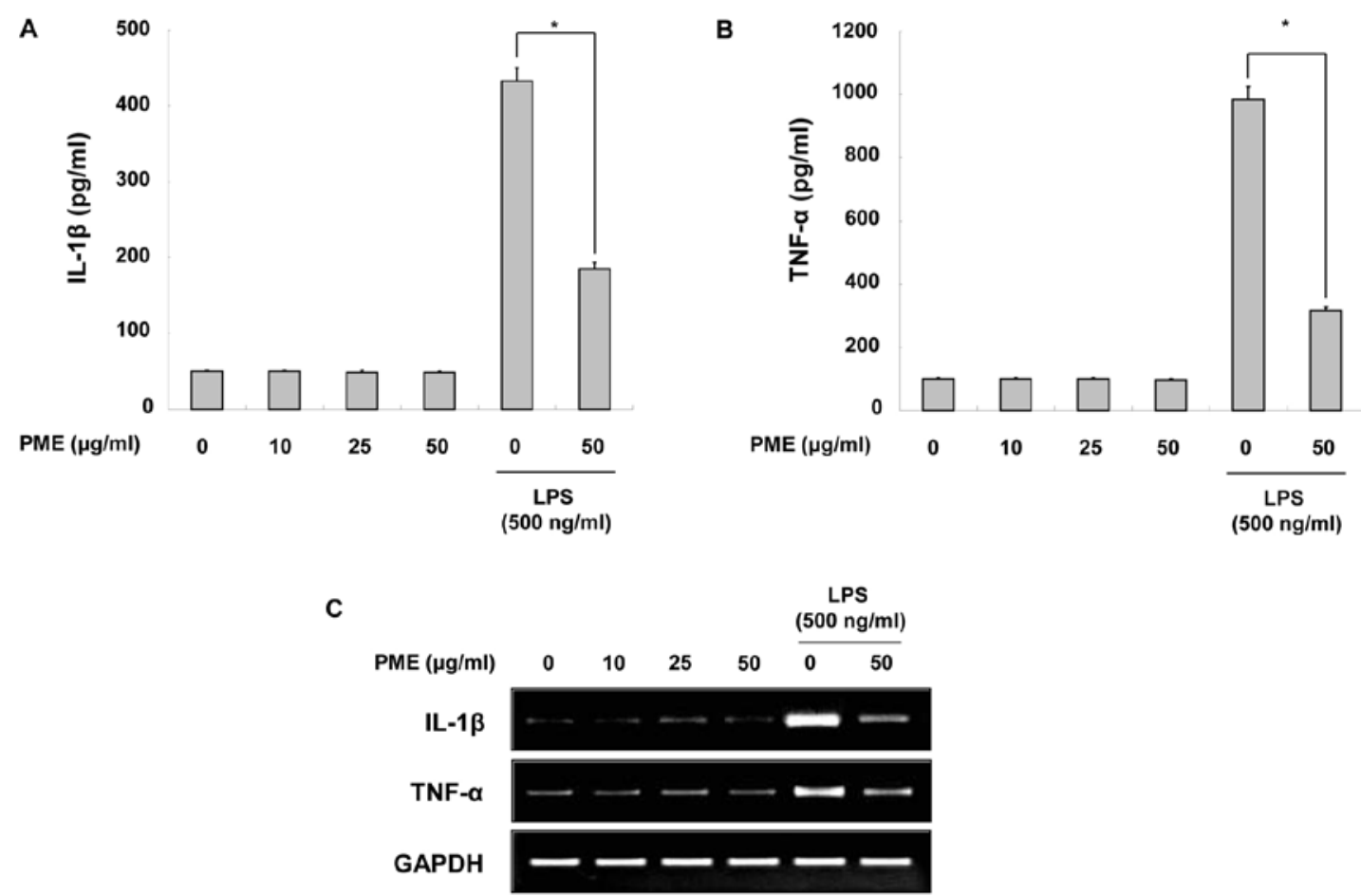

Figure 3. Effects of peat moss aqueous extract (PME) on lipopolysaccharide (LPS)-induced interleukin (IL)-1 $\beta$ and tumor necrosis factor (TNF)- $\alpha$ expression and production. RAW 264.7 cells were pre-treated with PME at the indicated concentrations for $1 \mathrm{~h}$ prior to LPS stimulation for $24 \mathrm{~h}$. (A and B) Production of IL- $1 \beta$ and TNF- $\alpha$ was measured by ELISA. Values are the means \pm SD. "P<0.05 compared with the LPS-treated group. (C) The mRNA level of IL- $1 \beta$ and TNF- $\alpha$ was evaluated by RT-PCR. GAPDH was used as an internal control for RT-PCR.

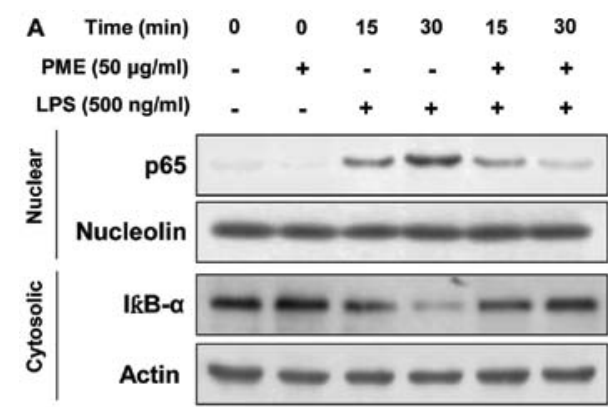

C

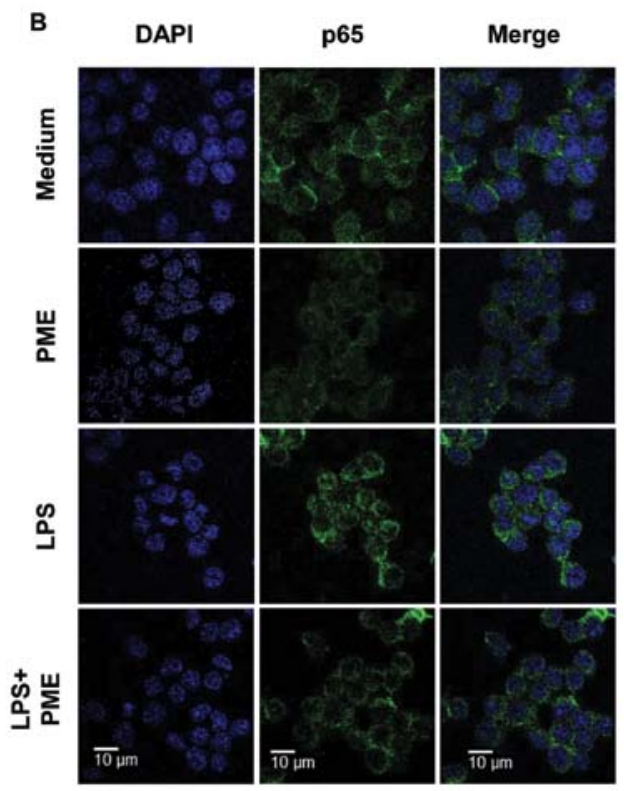

Figure 4. Effects of peat moss aqueous extract (PME) on lipopolysaccharide (LPS)-induced nuclear factor (NF)- $\kappa \mathrm{B}$ translocation and expression. (A) RAW 264.7 cells were pre-treated with $50 \mu \mathrm{g} / \mathrm{ml}$ PME for $1 \mathrm{~h}$ prior to LPS stimulation for 15 and $30 \mathrm{~min}$. Expression of nucleic p65, a subunit of NF- $\mathrm{B}$, and cytosolic I $\mathrm{B} \alpha$ was measured by western blot analysis. Nucleolin and actin were used as internal controls for the nuclear and cytosolic fractions, respectively. (B) RAW 264.7 cells were pre-treated with $50 \mu \mathrm{g} / \mathrm{ml}$ PME for $30 \mathrm{~min}$ prior to LPS stimulation for $30 \mathrm{~min}$. p65 expression was analyzed by immunofluorescence staining. For visualization, p65 and nucleus were treated with Alexa Fluor 488-tagged anti-rabbit IgG and DAPI, respectively. (C) Density ratios of nucleic p65 were measured by densitometry. All values are the means \pm standard deviation. ${ }^{*} \mathrm{P}<0.05$ compared with LPS-treated group.

tion (Fig. 4C). Compared with the LPS-stimulated RAW 264.7 cells, the PME-pre-treated cells maintained the basal levels of p65 intensity. Thus, PME disrupts the NF- $\kappa \mathrm{B}$ transloca- tion into the nucleus by helping to sustain $\mathrm{I} \kappa \mathrm{B} \alpha$ expression, resulting in the transcriptional regulation of iNOS, COX-2 and pro-inflammatory cytokines. 


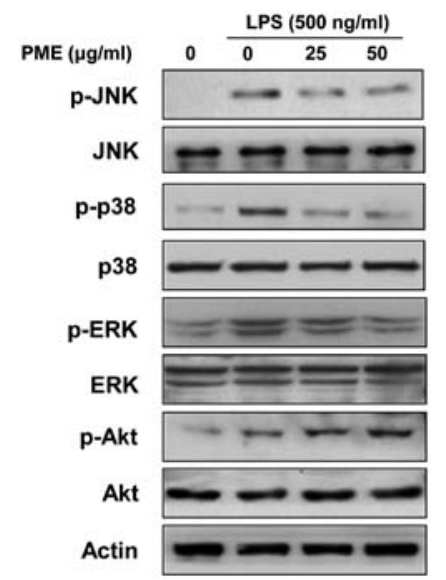

Figure 5. Effects of peat moss aqueous extract (PME) on the activation of mitogen-activated protein kinases (MAPKs) and Akt. RAW 264.7 cells were pre-treated with $50 \mu \mathrm{g} / \mathrm{ml} \mathrm{PME}$ for $1 \mathrm{~h}$ and then stimulated with lipopolysaccharide (LPS) for $30 \mathrm{~min}$. The expression of p38 MAPK, JNK, ERK and Akt was measured by western blot analysis. Actin was used as an internal control for western blot analysis.

Regulatory effects of PME on the activation of mitogenactivated protein kinases (MAPKs) and Akt. We examined whether the activation of MAPKs and Akt in LPS-stimulated RAW 264.7 cells is regulated by PME. LPS stimulation for 30 min activated all members of MAPKs. Pre-treatment with PME for $1 \mathrm{~h}$ suppressed the phosphorylation of MAPKs in a dose-dependent manner (Fig. 5). Although PME significantly attenuated the activation of p38 MAPK and ERK, JNK was less sensitively regulated than p38 MAPK and ERK. Akt activation was increased by LPS stimulation, and treatment with PME induced the further amplification of Akt activation in a concentration-dependent manner. Our results suggest that the inhibition of MAPK activation and the enhancement of Akt activation suppresses the inflammatory response in LPS-stimulated RAW 264.7 cells.

Regulatory effects of PME on $\mathrm{Nrf} 2$ and $\mathrm{HO}-1$ expression. As PME prevented cell death from $\mathrm{H}_{2} \mathrm{O}_{2}$-induced oxidative stress (Fig. 1), we hypothesized that pre-treatment with PME may enhance the expression of antioxidant enzymes in RAW 264.7 cells. We examined whether the expression of HO-1 and Nrf2 was regulated by PME. Initially, the RAW 264.7 cells were cultured with PME at the indicated concentrations for $12 \mathrm{~h}$. As shown by western blot analysis, PME gradually enhanced Nrf2 and HO-1 expression in a concentration-dependent manner (Fig. 6A). Using $50 \mu \mathrm{g} / \mathrm{ml}$ PME, protein induction was evident at $6 \mathrm{~h}$, and reached a maximum after $24 \mathrm{~h}$ of treatment with PME (Fig. 6B). We then examined the location of Nrf2 at $12 \mathrm{~h}$ using immunofluorescence staining. Immunofluorescent intensity in the nucleus showed that treatment with PME enhanced the translocation of Nrf2 into the nucleus (Fig. 6C and D). These results indicate that PME induces HO-1 expression by facilitating Nrf2 activation.

\section{Discussion}

Peat moss has been used for the investigation of the absorbance efficacy of irons, such as nickel and copper, and is potentially used for purging hazardous irons from polluted water $(14,15)$. In the biomedical field, hypersensitivity pneumonitis and chronic respiratory disorder of peat moss processing factory workers have been investigated $(16,17)$. However, to the best of our knowledge, the anti-inflammatory or antioxidant effects of PME have not been investigated to date. In the present study, we demonstrate the anti-inflammatory and antioxidant properties of PME in LPS-stimulated RAW 264.7 cells.
A

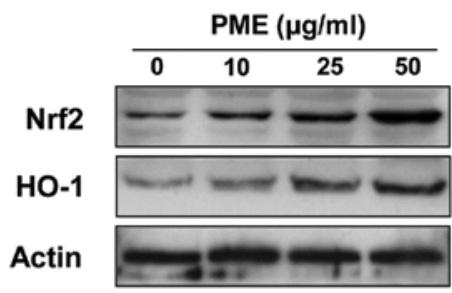

C

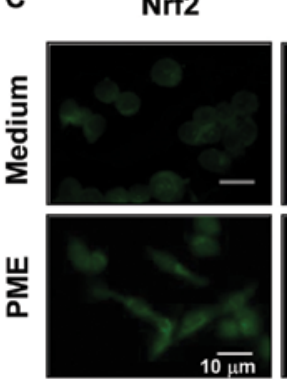

DAPI

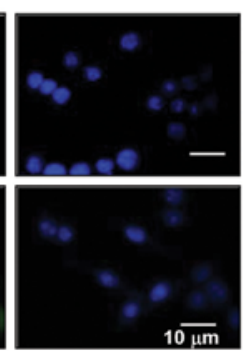

Merge

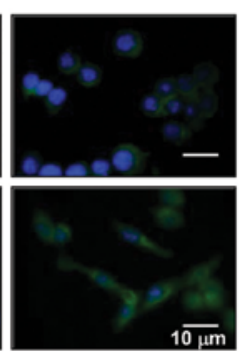

B
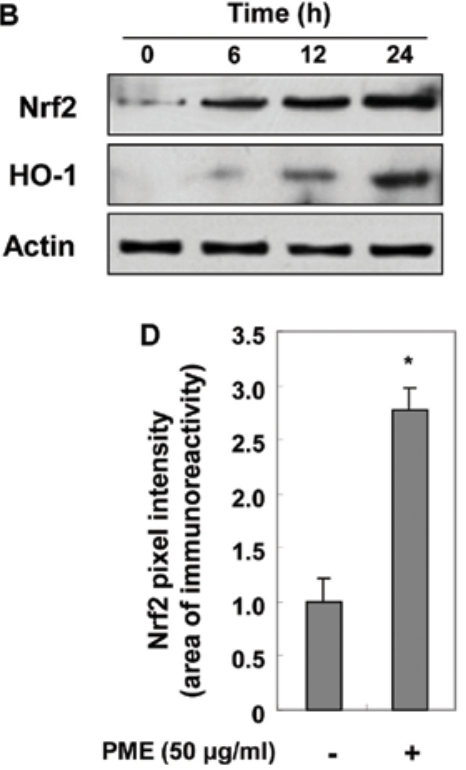

Figure 6. Effects of peat moss aqueous extract (PME) on the enhancement of nuclear factor-like 2 (Nrf2) and heme oxygenase-1 (HO-1) expression. (A and B) RAW 264.7 cells were treated PME at 10,25 and $50 \mu \mathrm{g} / \mathrm{ml}$ for $12 \mathrm{~h}$ (A) or $50 \mu \mathrm{g} / \mathrm{ml} \mathrm{PME}$ for different periods of time (B). Protein expression of Nrf2 and HO-1 was evaluated by western blot analysis. Actin was used as an internal control for western blot analysis. (C) RAW 264.7 cells were treated with $50 \mu \mathrm{g} /$ $\mathrm{ml} \mathrm{PME} \mathrm{for} 12 \mathrm{~h}$. For visualization, Nrf2 and nucleus were treated with Alexa Fluor 488-tagged anti-rabbit IgG and DAPI, respectively. (D) Density ratios of nucleic p65 were measured by densitometry. All values are the means $\pm \mathrm{SD}$. ${ }^{*} \mathrm{P}<0.05$ compared with the control group (medium only). 
In order to evaluate whether the inhibitory effects of PME on LPS-induced NO production, MTT assay was conducted. PME did not appear significantly cytotoxic to the RAW 264.7 cells, although it protected the cells against $\mathrm{H}_{2} \mathrm{O}_{2}$-induced oxidative stress. PME attenuated the LPS-induced $\mathrm{NO}$ and $\mathrm{PGE}_{2}$ production, accompanied by the downregulation of iNOS and COX-2 expression. In addition, in RAW 264.7 cells PME negatively regulated the synthesis of pro-inflammatory cytokines, including TNF- $\alpha$ and IL-1 $\beta$, at the transcriptional level. The results of the present study provide evidence that PME induces the anti-inflammatory response in LPS-stimulated RAW 264.7 cells. The inducible enzymes (iNOS and COX-2) and their reaction products are associated with inflammatory diseases. Both enzymes are upregulated in the inflammatory response, and their reactive products, $\mathrm{NO}$ and $\mathrm{PGE}_{2}$, respectively, are closely related to various chronic diseases, such as ulcers and RA $(18,19)$. TNF- $\alpha$ and IL-1 $\beta$ secreted from activated monocytes and macrophages exerts a vareity of pro-inflammatory effects on many cell types (20). These cytokines are important in chronic inflammation, such as RA (21). Even though our experiments were conducted under acute inflammatory conditions, our results provide valuable information on the regulatory effects of PME on macrophages, cells critical in the process of chronic inflammation (22). There is evidence that a folk remedy, a mud bath including peat, relieves the symptoms of RA (23). Based on our results, peat moss may have anti-inflammatory abilities in acute inflammatory responses, which potentially ameliorates chronic inflammation, including rheumatoid diseases.

The LPS-induced expression of the iNOS, COX-2 pro-inflammatory cytokines was regulated by PME at the transcriptional level. In order to examine whether the inhibitory effects of PME are mediated through the inactivation of $\mathrm{NF}-\kappa \mathrm{B}$, western blot analysis for nuclear p65 and cytosolic I $\kappa \mathrm{B} \alpha$ and a microscopic observation for $\mathrm{p} 65$ were performed in the present study. Pre-treatment with PME led to a significant decrease in nuclear p65 levels and an increase in cytosolic I $\kappa \mathrm{B} \alpha$ levels. The inhibitory effects of PME on p65 translocation into the nucleus and p65 expression were also shown by microscopic observation (Fig. 4). NF- $\kappa \mathrm{B}$ has been implicated in the induction of the expression of iNOS and COX-2 protein. $\mathrm{NF}-\kappa \mathrm{B}$ is primarily composed of two proteins, p65 and p50. In the resting state, $\mathrm{NF}-\kappa \mathrm{B}$ can be found in the cytosol and is bound to the inhibitory protein, $\mathrm{I} \kappa \mathrm{B}$. The activation of cells with various stimuli initiates I $\mathrm{K}$ B phosphorylation, which triggers proteolytic degradation. $N F-\kappa B$ is then released from the inactive complex, and translocates to the nucleus (24). Nuclear NF- $\kappa B$ binds to the $\kappa B$ binding sites in the promoter regions of target genes. NF- $\kappa \mathrm{B}$ response elements are present on the promoters of iNOS and COX-2 (24,25). NF- $\mathrm{BB}$ is also involved in the transcription of TNF- $\alpha$ and IL-1 $\beta$ (26). Our findings suggest that the inhibition of NF- $\kappa \mathrm{B}$ by PME may be due to the inhibition of $\mathrm{I} \kappa \mathrm{B} \alpha$ phosphorylation, thereby suppressing the translocation of $\mathrm{p} 65$. Therefore, the PME-mediated regulation of the expression of iNOS, COX-2, and pro-inflammatory cytokines was induced by the inhibition of $\mathrm{NF}-\kappa \mathrm{B}$ activation.

LPS-stimulated signaling events in macrophages lead to the activation of several MAPK signaling pathways. MAPKs consist of three major members, including ERK, p38 MAPK and JNK, which are activated by MAPK kinases (MEKs) in LPS-stimulated macrophages. Although LPS stimulation activates all MAPK families, each kinase can be differentially activated in response to a particular stimuli. In the case of ERK activation, growth factors and phorbol esters play roles as stimulators. JNK and p38 MAPK are selectively activated by cellular stress, UV light and osmosis $(27,28)$. LPS-induced MAPK activation leads to the expression of iNOS, COX-2, TNF- $\alpha$ and IL-1 $\beta$ in macrophages. The activation of ERK and p38 MAPK is related to the expression of COX-2, TNF- $\alpha$ and IL-1 $\beta$. ERK and p38 MAPK activates cyclic AMP response element-binding protein (CREB) through mitogen- and stressactivated protein kinase (MSK)-1, resulting in the expression of COX- 2 and IL- $1 \beta$. In the case of IL-1 $\beta$, the activation of MAP kinase-activated protein kinase 2 (MAPKAP-K2) by p38 MAPK mainly regulates IL-1 $\beta$ expression (29). iNOS expression by LPS stimulation is augmented by JNK activation. In LPS-stimulated macrophages, p38 MAPK counteracts JNK which suppresses iNOS expression. Treatment with SB203580, a p38 MAPK inhibitor, facilitates JNK phosphorylation and iNOS expression (30). In the present study, the activation of JNK, p38 MAPK and ERK was downregulated by PME in a concentration-dependent manner, suggesting that the inactivation of MAPKs by PME induces the downregulation of iNOS, COX-2, TNF- $\alpha$ and IL- $1 \beta$.

Previous studies have indicated that PI3K/Akt-linked cascades are involved in the negative regulation of LPS-induced inflammatory responses $(31,32)$. The present study investigated the effects of PME on Akt activation in LPS-stimulated RAW 264.7 cells. Our findings showed that Akt activation was increased by LPS stimulation, and was further enhanced by PME treatment (Fig. 5). Consistent with our results, resveratrol has been shown to enhance Akt activation which is mediated by the inhibition of inflammatory responses in LPS-stimulated RAW 264.7 cells. Treatment of LPS-stimulated RAW 264.7 cells with resveratrol augmented Akt activation, resulting in the downregulation of iNOS, COX-2, and TNF- $\alpha$ expression. However, the regulatory effects of resveratrol on the expression of inflammatory mediators were not induced under PI3Kinhibited conditions (33). As Akt activation is required for the inactivation of MAPKs, resveratrol does not appear to have anti-inflammatory effects under PI3K-inhibited conditions. Similarly, malvidin, a major red wine polyphenol, appears to have anti-inflammatory effects in LPS-stimulated macrophages through Akt activation. Treatment with malvidin amplified Akt activation in LPS-stimulated macrophages, playing a protective role in LPS-induced mitochondrial depolarization (34). In addition, Akt activation is closely associated with the induction of antioxidant effects through Nrf2 activation. The inhibition of PI3K leads to the reduction of Nrf2 activation, resulting in a decrease in HO-1 expression $(35,36)$. Our results are consistent with these studies, in that the expression of Nrf2 and HO-1 was augmented by PME in unstimulated RAW 264.7 cells. Based on previous studies, our data suggest that the anti-inflammatory and antioxidant effects of PME are induced through the activation of Akt.

HO-1 belongs to a larger family of stress proteins whose transcriptional regulation also responds to cellular injury, including thermal or oxidant stress, and protects cells against stress (37). HO-1 plays a role as a rate-limiting enzyme in the production of bilirubin. In this reaction, hemin-induced HO-1 catalyzes the conversion of heme into biliverdin which is then 
changed into bilirubin, possessing antioxidant abilities $(38,39)$. Studies have demonstrated that curcumin, a phenolic compound, prevents oxidative stress by increasing HO-1 activity $(40,41)$. Elevated HO-1 activity induces an increase in glutathione levels in astrocytes. Furthermore, under hypoxic conditions, curcumin significantly amplifies HO-1 activity in vascular endothelial cells, protecting the cells against oxidative stress. In the case of Nrf2, it is a basic leucine zipper transcription factor activating the antioxidant response element (ARE) in the promoters of antioxidant genes. These data suggest that the expression of HO-1 is related to the antioxidative process (42). $\mathrm{Nrf} 2$ is sequestered in the cytosol by Keap1. Upon stimulation, Nrf2 is released from Keap1 and translocates to the nucleus to activate ARE on the HO-1 promoter (43). In addition, HO-1 negatively regulates iNOS expression in LPS-stimualted RAW 264.7 cells. A previous study on the anti-inflammatory effects of genipin, an aglycon of geniposide, proved that the inhibitory effects of genipin on iNOS expression are supressed in HO-1-inhibited RAW 264.7 cells (44). Based on these previous studies, HO-1 and Nrf2 participate in antioxidant and anti-inflammatory processes. In the present study, pre-treatment with PME enhanced the viability of $\mathrm{H}_{2} \mathrm{O}_{2}$-treated RAW 264.7 cells (Fig. 1), and increased Nrf2 activation and HO-1 expression in intact RAW 264.7 cells (Fig. 6). Hence, our data indicate that PME increases Nrf2 activation and HO-1 expression which may lead to the prevention of oxidative stress-induced cell death and supports the negative regulation of iNOS expression in LPS-stimulated RAW 264.7 cells.

In conclusion, PME exerts an anti-inflammatory effects by regulating the production of pro-inflammatory mediators through the downregulation of NF- $\mathrm{KB}$ phosphorylation, and the inactivation of p38 MAPK and JNK in LPS-stimulated RAW 264.7 cells. Under oxidative conditions, PME improved cell viability by augmenting Nrf2 activation and HO-1 expression. These results suggest that PME may be a promising candidate for the treatment of inflammatory diseases by regulating inflammatory macrophages.

\section{Acknowledgements}

The present study was supported by the R\&D Program of MKE/KEIT (10040391, Development of Functional Food Materials and Device for Prevention of Aging-associated Muscle Function Decrease) and the Blue-Bio Industry Regional Innovation Center (RIC08-06-07) at Dongeui University as a RIC program under MKE and Busan, Republic of Korea. This study was also supported by a grant from the Next Generation BioGreen 21 Program (SSAC, grant no. PJ009615), Rural Development Administration, Republic of Korea.

\section{References}

1. Medzhitov R: Inflammation 2010: new adventures of an old flame. Cell 140: 771-776, 2010

2. Jaffrey SR and Snyder SH: Nitric oxide: a neural messenger. Annu Rev Cell Dev Biol 11: 417-440, 1995.

3. Won JS, Im YB, Singh AK and Singh I: Dual role of cAMP in iNOS expression in glial cells and macrophages is mediated by differential regulation of $\mathrm{p} 38$-MAPK/ATF-2 activation and iNOS stability. Free Radic Biol Med 37: 1834-1844, 2004.

4. Hu C and Kitts DD: Luteolin and luteolin-7-O-glucoside from dandelion flower suppress iNOS and COX-2 in RAW264. 7 cells. Mol Cell Biochem 265: 107-113, 2004.
5. Salvemini D, Misko TP, Masferrer JL, Seibert K, Currie MG and Needleman P: Nitric oxide activates cyclooxygenase enzymes. Proc Natl Acad Sci USA 90: 7240-7244, 1993.

6. Tak PP: A personalized medicine approach to biologic treatment of rheumatoid arthritis: a preliminary treatment algorithm. Rheumatology 51: 600-609, 2012.

7. Ahn JK, Huang B, Bae EK, et al: The role of $\alpha$-defensin-1 and related signal transduction mechanisms in the production of IL-6, IL-8 and MMPs in rheumatoid fibroblast-like synoviocytes. Rheumatology 52: 1368-1376, 2013.

8. Cocozza C, D'orazio V, Miano T and Shotyk W: Characterization of solid and aqueous phases of a peat bog profile using molecular fluorescence spectroscopy, ESR and FT-IR, and comparison with physical properties. Org Geochem 34: 49-60, 2003.

9. Bonifacio E, Falsone G and Petrillo M: Humus forms, organic matter stocks and carbon fractions in forest soils of northwestern Italy. Biol Fert Soils 47: 555-566, 2011.

10. Schepetkin I, Khlebnikov A and Kwon BS: Medical drugs from humus matter: focus on mumie. Drug Develop Res 57: 140-159, 2002.

11. Van Rensburg CE, Snyman JR, Mokoele T and Cromarty AD: Brown coal derived humate inhibits contact hypersensitivity; an efficacy, toxicity and teratogenicity study in rats. Inflammation 30 : 148-152, 2007.

12. Jooné GK and van Rensburg CE: An in vitro investigation of the anti-inflammatory properties of potassium humate. Inflammation 28: 169-174, 2004.

13. Van Rensburg CE and Naude PJ: Potassium humate inhibits complement activation and the production of inflammatory cytokines in vitro. Inflammation 32: 270-276, 2009.

14. Ho Y, John Wase D and Forster C: Batch nickel removal from aqueous solution by sphagnum moss peat. Water Res 29: 1327-1332, 1995.

15. Gardea-Torresdey J, Tang L and Salvador J: Copper adsorption by esterified and unesterified fractions of Sphagnum peat moss and its different humic substances. J Hazard Mater 48: 191-206, 1996.

16. Cormier Y, Israel-Assayag E, Bedard G and Duchaine C: Hypersensitivity pneumonitis in peat moss processing plant workers. Am J Respir Crit Care Med 158: 412-417, 1998.

17. Cormier Y, Boulet LP and Bérubé-Genest F: Effects of chronic organic dust exposure on respiratory function and airway responsiveness in peat moss factory workers. Arch Environ Health 45: 20-23, 1990.

18. Sakurai H, Kohsaka H, Liu MF, et al: Nitric oxide production and inducible nitric oxide synthase expression in inflammatory arthritides. J Clin Invest 96: 2357-2363, 1995.

19. Abd-El-Aleem SA, Ferguson MW, Appleton I, Bhowmick A, McCollum CN and Ireland GW: Expression of cyclooxygenase isoforms in normal human skin and chronic venous ulcers. J Pathol 195: 616-623, 2001.

20. Gayathri B, Manjula N, Vinaykumar K, Lakshmi B and Balakrishnan A: Pure compound from Boswellia serrata extract exhibits anti-inflammatory property in human PBMCs and mouse macrophages through inhibition of TNF $\alpha$, IL-1 $\beta$, NO and MAP kinases. Int Immunopharmacol 7: 473-482, 2007.

21. Dayer JM: The process of identifying and understanding cytokines: from basic studies to treating rheumatic diseases. Best Pract Res Clin Rheumatol 18: 31-45, 2004.

22. Lefkowitz DL, Mills K, Lefkowitz S, Bollen A and Moguilevsky N: Neutrophil-macrophage interaction: a paradigm for chronic inflammation. Med Hypotheses 44: 58-62, 1995.

23. Naudé P, Cromarty AD and van Rensburg CE: Potassium humate inhibits carrageenan-induced paw oedema and a graft-versushost reaction in rats. Inflammopharmacology 18: 33-39, 2010.

24. Neurath M, Becker C and Barbulescu K: Role of NF- $\kappa$ B in immune and inflammatory responses in the gut. Gut 43: 856-860, 1998.

25. Schmedtje JF, Ji YS, Liu WL, DuBois RN and Runge MS: Hypoxia induces cyclooxygenase-2 via the NF- $\kappa \mathrm{B}$ p 65 transcription factor in human vascular endothelial cells. J Biol Chem 272: 601-608, 1997.

26. O'Neill LA and Kaltschmidt C: NF- $\kappa$ B: a crucial transcription factor for glial and neuronal cell function. Trends Neurosci 20: 252-258, 1997.

27. Robinson MJ and Cobb MH: Mitogen-activated protein kinase pathways. Curr Opin Cell Biol 9: 180-186, 1997.

28. Cobb MH and Goldsmith EJ: How MAP kinases are regulated. J Biol Chem 270: 14843-14846, 1995. 
29. Caivano $\mathrm{M}$ and Cohen P: Role of mitogen-activated protein kinase cascades in mediating lipopolysaccharide-stimulated induction of cyclooxygenase-2 and IL-1 $\beta$ in RAW264 macrophages. J Immunol 164: 3018-3025, 2000.

30. Chan ED and Riches DW: IFN- $\gamma^{+}$LPS induction of iNOS is modulated by ERK, JNK/SAPK, and p38 mapk in a mouse macrophage cell line. Am J Physiol Cell Physiol 280: C441-C450, 2001.

31. Rajaram MV, Ganesan LP. Parsa KV, Butchar JP, Gunn JS and Tridandapani S: Akt/protein kinase B modulates macrophage inflammatory Response to Francisella infection and confers a survival advantage in mice. J Immunol 177: 6317-6324, 2006.

32. Zhang WJ, Wei H, Hagen T and Frei B: $\alpha$-lipoic acid attenuates LPS-induced inflammatory responses by activating the phosphoinositide 3-kinase/Akt signaling pathway. Proc Natl Acad Sci USA 104: 4077-4082, 2007.

33. Zong Y, Sun L, Liu B, Deng YS, Zhan D, Chen YL, He Y, Liu J, Zhang ZJ, Sun J and Lu D: Resveratrol inhibits LPS-induced MAPKs activation via activation of the phosphatidylinositol 3-kinase pathway in murine RAW 264.7 macrophage cells. PLoS One 7: e44107, 2012.

34. Bognar E, Sarszegi Z, Szabo A, Debreceni B, Kalman N, Tucsek Z, Sumegi B and Gallyas F Jr: Antioxidant and antiinflammatory effects in RAW 264.7 macrophages of malvidin, a major red wine polyphenol. PLoS One 8: e65355, 2013.

35. Wang L, Chen Y, Sternberg P and Cai J: Essential roles of the PI3 kinase/Akt pathway in regulating Nrf2-dependent antioxidant functions in the RPE. Inverst Ophthalmol Vis Sci 49: 1671-1678, 2008

36. Zou W, Chen C, Zhong Y, An J, Zhang X, Yu Y, Yu Z and Fu J: PI3K/Akt pathway mediates Nrf2/ARE activation in human L02 hepatocytes exposed to low-concentration HBCDs. Environ Sci Technol 47: 12434-12440, 2013.
37. Hoetzel A, Vagts DA, Loop T, et al: Effect of nitric oxide on shock-induced hepatic heme oxygenase-1 expression in the rat. Hepatology 33: 925-937, 2001.

38. Stocker R, Yamamoto Y, McDonagh AF, Glazer AN and Ames BN: Bilirubin is an antioxidant of possible physiological importance. Science 235: 1043-1046, 1987.

39. Mitani K, Fujita H, Fukuda Y, Kappas A and Sassa S: The role of inorganic metals and metalloporphyrins in the induction of haem oxygenase and heat-shock protein 70 in human hepatoma cells. Biochem J 290: 819-825, 1993.

40. Scapagnini G, Foresti R, Calabrese V, Stella AG, Green C and Motterlini R: Caffeic acid phenethyl ester and curcumin: a novel class of heme oxygenase-1 inducers. Mol Pharmacol 61: 554-561, 2002.

41. Motterlini R, Foresti R, Bassi R and Green CJ: Curcumin, an antioxidant and anti-inflammatory agent, induces heme oxygenase-1 and protects endothelial cells against oxidative stress. Free Radic Biol Med 28: 1303-1312, 2000.

42. Kobayashi A, Kang MI, Okawa H, et al: Oxidative stress sensor Keap1 functions as an adaptor for Cul3-based E3 ligase to regulate proteasomal degradation of Nrf2. Mol Cell Biol 24: 7130-7139, 2004.

43. Itoh K, Mochizuki M, Ishii Y, et al: Transcription factor Nrf2 regulates inflammation by mediating the effect of 15-deoxy$\Delta^{12,14}$-prostaglandin $\mathbf{J}_{2}$. Mol Cell Biol 24: 36-45, 2004.

44. Jeon WK, Hong HY and Kim BC: Genipin up-regulates heme oxygenase-1 via PI3-kinase-JNK1/2-Nrf2 signaling pathway to enhance the anti-inflammatory capacity in RAW264.7 macrophages. Arch Biochem Biophys 512: 119-125, 2011. 